\title{
Evaluation of the Toxicity of Three Hair Shampoos on the Catfish (Clarias gariepinus) Fingerlings
}

\author{
Ogbuagu D.H. ${ }^{1, *}$, Iwuchukwu E.I. ${ }^{2}$ \\ ${ }^{1}$ Department of Environmental Technology, Federal University of Technology, PMB 1526, Owerri, Nigeria \\ ${ }^{2}$ Department of Agricultural Engineering, Federal Polytechnic, Nekede, PMB 1036, Owerri, Nigeria \\ *Corresponding author: henrydike2002@yahoo.com
}

Received April 22, 2014; Revised June 07, 2014; Accepted July 02, 2014

\begin{abstract}
The toxicity of three brands of hair shampoos (Vinoz, Gentelle and Petals) containing linear alkylbenzene sulphonates and used mostly for hair conditioning in beauty shops by woman in Nigeria were evaluated on fingerlings of the African catfish, Clarias gariepinus (mean weight=6.42 $\pm 0.2 \mathrm{~g}$; length $=4.03 \pm 0.1 \mathrm{~cm}$ ). Specimens were exposed to $0.50 \%, 0.25 \%, 0.125 \%, 0.0625 \%, 0.03125 \%$ and $0.00 \%$ (control) toxicant concentrations during a 96-hours static bioassay. Mortality increased with concentrations and varied with brand of shampoo used; with the $0.50 \%$ toxicant concentration and Vinoz shampoo showing highest toxicity. $\mathrm{LC}_{50}$ for Vinoz, Gentelle and Petals were $0.0195 \%, 0.0281 \%$ and $0.0281 \%$ (arithmetic method), $0.9058 \%, 0.8873 \%$ and $0.8710 \%$ (logarithmic method) and $0.0172 \%, 0.0281 \%$ and $0.0177 \%$ (probit method) respectively. Survivorship of $C$. gariepinus was significantly homogeneous with Vinoz $\left[\mathrm{F}_{(1.56)}<\mathrm{F}_{\text {crit(4.13) }}\right]$, heterogeneous with Gentelle $\left[\mathrm{F}_{(4.31)}>\mathrm{F}_{\text {crit(4.13) }}\right]$ and heterogeneous with Petals shampoos $\left[\mathrm{F}_{(5.57)}>\mathrm{F}_{\text {crit(4.13) }}\right]$ at $\mathrm{P}<0.05$. The numbers of survivors in the 0.125 and $0.03125 \%$ toxicant concentrations differed significantly with those in the control (Sig. $t=0.001 \& 0.002$ with Vinoz and $=0.002 \& 0.003$ with Gentelle, respectively) at the $95 \%$ confidence limit. Very low mean lethal concentrations of the xenobiotics exerted high toxicities on the aquatic biota. Regulatory agencies should enforce strict laws for the protection of the national aquatic biotopes for sustainability.
\end{abstract}

Keywords: surfactants, toxicity, bioassay, $L C_{50}$, mortality, xenobiotics

Cite This Article: Ogbuagu D.H., and Iwuchukwu E.I., "Evaluation of the Toxicity of Three Hair Shampoos on the Catfish (Clarias gariepinus) Fingerlings." Applied Ecology and Environmental Sciences, vol. 2, no. 3 (2014): 86-89. doi: 10.12691/aees-2-3-3.

\section{Introduction}

Surfactants are synthetic organic chemicals used in detergents, personal care and household cleaning. These compounds usually comprise $10 \%-18 \%$ of granular and liquid detergents and are the largest ingredient of the 2025 compounds used in these products [1]. Hair shampoo is a liquid detergent used mostly by women in conditioning and washing their hair. In Owerri, the Imo State capital and many other Nigerian cities and the hinterlands for example, the establishment of hair dressing saloons is on the increase probably because of modernization and the quest for fashion especially among women. The effluents (wastewater) from these saloons empty into water bodies in their proximity via gutters and urban drains and thus, could pollute them [2] in especially, Sub-Saharan Africa where there are little or no prohibitions for violators.

Beautification is one of man's body care process that involves the heavy and prolific use of surfactants, which are basically ingredients of body care products. They are known to reduce surface tension in water and allow aqueous solutions to spread and penetrate more easily. Thus, their inclusion in body shampoos enable intended effects of other ingredients to permeate the target body areas such as face, hair, skin etc. Unfortunately, these same characteristics could adversely affect aquatic lives [3], such as altering the properties of a fish's gills and subsequently change the fish's normal uptake of ions from the water column [4,5]. Other effects could include tainting of the fish's body, bioaccumulation of the toxicant in fish tissues or even mortality [6,7]. Unfortunately, the possible toxic effects of these inorganic pollutions have not been investigated in our local environment, against its increasing use and introduction of newer brands by manufacturers. This research therefore was an attempt to close this gap in knowledge, through the evaluation of the toxicity of effluents of three commonly used hair shampoos (Vinoz, Gentelle and Petals) in Owerri Metropolis, southestern Nigeria, on the popular fish delicacy- Clarias gariepinus.

\section{Materials and Methods}

An The scientific methods employed in this study were in keeping with standard protocols of Buikema and Cairns [8], Bellan [9], Ward and Parrish [10,11] and Reish and Oshida [12,13].

\subsection{Study Area}


The Pollution Control Laboratory of the Department of Environmental Technology, Federal University of Technology, Owerri (FUTO), Nigeria where the research was carried out is in Owerri West Local Government Area of Imo State, Southeastern Nigeria. FUTO lies between latitudes $05^{\circ} 22^{\prime}$ and $05^{\circ} 39^{\prime}$ and longitudes $06^{\circ} 08^{\prime}$ and $06^{\circ} 41^{\prime}$, near Ihiagwa town.

\subsection{Acquisition and Acclimation of Fish Specimens}

Healthy specimens of the African catfish, C. gariepinus of mixed sex and broodstock (mean weight $=6.42 \pm 0.2 \mathrm{~g}$; mean length $=4.30 \pm 0.1 \mathrm{~cm}$ ) were purchased from a fish farm in Owerri. The choice of $C$. gariepinus was made because of its ability to withstand stress and its high commercial value in Nigeria. They were maintained in the laboratory in a large plastic bowl of about 120 litres capacity containing 60 litres of clean borehole water for a minimum period of two weeks for acclimation during which period they were fed 3 times daily (morning, afternoon and night) with commercial fish pellets. Threequarters of the water was changed every morning at feeding time to reduce constant dirt occasioned by the feed pellets and the fish faeces. However, feeding was discontinued 24 hours before commencement of definitive experiment.

\subsection{Determination of Physicochemical Properties of Diluent Water}

The temperature, Dissolved Oxygen (DO) and $\mathrm{pH}$ of experimental water were continuously determined in-situ with a pre-calibrated HANNA HI 9828 PH/ORP/EC/DO meter.
Hair-care shampoos essentially contain linear alkylbenzene sulphonates and fragrance formulations. The specific chemical compositions of the toxicants used in this study are shown in Table 1.

\subsection{Range-finding Test}

Ten fish of approximately same sizes were distributed randomly into each of 5 plastic aquaria containing 60 litres of borehole water. Graded concentrations (5, 4, 3, 2 and $1 \%$ ) of each of the toxicants were serially added to the aquaria and the set $\neg$ ups allowed to stand for 96 hours. Observations for death of fish were made after $1,2,4,8$, $16,24,48,72$, and 96 hours. After the 96th hour, only the $1 \%$ diluent water-toxicant setup had live fish, while $100 \%$ mortalities were recorded in the other toxicant concentration setups.

\subsection{Definitive Static Bioassay}

Definitive graded concentrations of $0.5,0.25,0.125$, $0.0625,0.03125$ and $0.00 \%$ (control) for each toxicant was constituted in 6 aquaria containing 60 litres of diluents water. Ten fish specimens were added to each of the aquarium. Replicate aquaria were also established and the setup observed for mortalities after 1, 2, 4, 8, 16, 24, 72 and 96 hours. Death was ascertained when fish did not react to gentle poke with a glass rod and was immediately removed to avoid decay and contamination. Loss of equilibrium, vigorous movement of gulping of air and other behavioural patterns were also observed for fish in each plastic aquarium. While the experiment lasted, there were no mortalities in the control aquaria. The test fish were not fed to prevent remnants of uneaten food from contaminating the water thereby increasing mortality rates.

\subsection{Active ingredients of Toxicants}

Table 1. Chemical compositions of the three hair shampoos used as toxicant in 96-hours bioassay

\begin{tabular}{|c|c|c|}
\hline \multicolumn{3}{|c|}{ Hair shampoos } \\
\hline Vinoz & Gentelle & Petals \\
\hline $\begin{array}{l}\text { Deionized water, antisol, } \\
\text { menthol, soda ash, sodium } \\
\text { laureth sulphate, euxyl, } \\
\text { common salt, methyl } \\
\text { salicylate, colourant and } \\
\text { fragrance }\end{array}$ & $\begin{array}{l}\text { Aqua, sodium laureth sulfate, sodium chloride, cocamidopropyl betaine, parfum, } \\
\text { glycol stearate, cocamideMEA, disodium EDTA, citric acid, sodium Hydroxide, } \\
\text { triethylene glycol, benzyl alcohol, propylene glycol, sodium benzoate, tetrasodium } \\
\text { EDTA, magnesium chloride, magnesium nitrate, methylchlorois othiazolinone, } \\
\text { methylisothiazolinone, jasminum officinale, methylparaben and sorbic acid }\end{array}$ & $\begin{array}{l}\text { Alkylbenzene sulphate, soda } \\
\text { ash(light), sodium hydroxide, } \\
\text { methyl paraben, colourant, } \\
\text { fragrance, De-ionised water } \\
\text { and CMC }\end{array}$ \\
\hline
\end{tabular}

\subsection{Statistical Analysis}

Mean lethal concentrations $\left(\mathrm{LC}_{50}\right)$ of the toxicants used were calculated using the arithmetic, logarithmic and probit methods. The single factor ANOVA was used to determine variance equality in means of survival rates of fish specimens, while post-hoc structure of group means was detected with means plots at $\mathrm{P}<0.05$. A pairwise comparison of survival rates in the different concentrations of toxicants was conducted with the student's t-test of significance at the 95\% confidence interval.

\section{Results}

Mean room temperature was $24.3 \pm 0.2^{\circ} \mathrm{C}$ throughout the experimental period.

\subsection{Mortality of C. gariepinus in Vinoz Hair Shampoo}

Mortality patterns in replicates 1, 2 and 3 (Figure 1) reveal that 1 fish each survived after 96 hours in the $0.5 \%$ and $0.25 \%$ toxicant concentrations; in replicates 1 and 2, 1 fish each survived in the $0.125 \%$ concentration; and in replicate 3 of the same $(0.125 \%)$ concentration, 2 fish survived. In the $0.0625 \%$ toxicant concentration, 2 fish each survived in replicates 1,2 and 3 after 96 hour exposure period, whereas in the $0.03125 \%$ toxicant concentration, replicate 1 recorded 2 survivors and replicates 2 and 3 recorded 3 survivors each. However, replicates 1, 2 and 3 of the control experiment recorded $100 \%$ survivals after the 96 hours. However, a test of homogeneity in mean variance of numbers of survivors among C. gariepinus exposed to Vinoz Shampoo revealed 
homogeneity $\left[\mathrm{F}_{(1.56)}<\mathrm{F}_{\text {crit(4.13) }}\right]$ at $\mathrm{P}<0.05$. The mean $\mathrm{pH}$ of the experimental setup was $5.2 \pm 1.0$, temperature was $24.0 \pm 0.4^{\circ} \mathrm{C}$ while DO was $2.1 \pm 1.4 \mathrm{mg} / \mathrm{L}$ over 96 hours period.

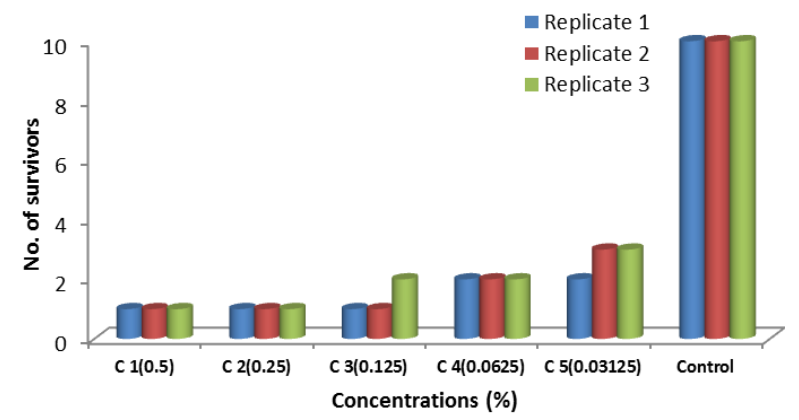

Figure 1. Survival of fingerlings of C. gariepinus (10 animals) exposed to Vinoz shampoo over 96 hours

\subsection{Mortality of C. gariepinus in Gentelle Hair Shampoo}

The mortality trend in replicates 1, 2 and 3 (Figure 2) of the $0.5 \%$ and $0.125 \%$ toxicant concentrations revealed that only 1 fish survived after 96 hours exposure. Replicate 1 of the $0.125 \%$ toxicant concentration recorded 1 survivor while 2 survived in replicates 2 and 3 of the same toxicant concentration. The $0.0625 \%$ toxicant concentration recorded 3 survivors each in replicates 1,2 and 3 , while 5 fish survived in replicate 1 of the $0.03125 \%$ toxicant concentration. Four fish survived in each of replicates 2 and 3 after 96 hour exposure, while all 10 fish survived in replicates 1, 2 and 3 of the control setup after the 96-hour bioassay. Mean pH, temperature and DO of the toxicant/diluent water was as follows: $5.2 \pm 1.0,26.7 \pm$ $0.10 \mathrm{C}$, and $3.7 \pm 1.3 \mathrm{mg} / \mathrm{L}$ over the 96 hours period. There was significant heterogeneity in mean survival of fish species at $\mathrm{P}<0.05\left[\mathrm{~F}_{(4.31)}>\mathrm{F}_{\text {crit(4.13) }}\right]$.

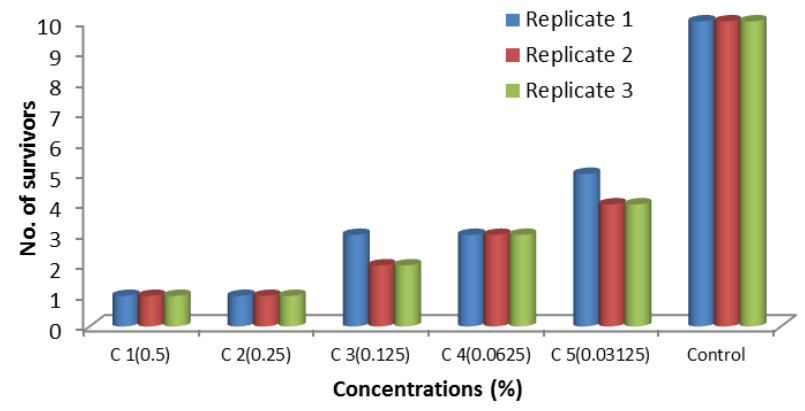

Figure 2. Survival of fingerlings of C. gariepinus (10 animals) exposed to Gentelle shampoo over 96 hours

\subsection{Mortality of C. gariepinus in Petals Hair Shampoo}

In replicates 1,2 and 3 of the $0.5 \%$ toxicant concentration, 1 fish each survived after the 96 hours bioassay (Fig. 3). In the $0.25 \%$ concentration, replicate 1 recorded 2 survivors while replicates 2 and 3 recorded 1 survivor each. In replicates 1, 2 and 3 of the $0.125 \%$ toxicant concentration, 2 fish each survived, in replicates 1 and 2 of the $0.0625 \%$ toxicant concentration, only 4 fish survived in each of them while in replicate 3 of the same toxicant concentration, 3 fish survived. Five fish each survived after 96- hour exposure in replicates 1, 2 and 3 of the $0.03125 \%$ toxicant concentration. All fish specimens in the control aquaria also survived after the 96-hours bioassay period. The ANOVA test in mean survivals revealed significant heterogeneity $\left[\mathrm{F}_{(5.57)}>\mathrm{F}_{\text {crit(4.13) }}\right]$ at $\mathrm{P}<0.05$. In this toxicant/diluents water mixture, mean $\mathrm{pH}$, temperature and DO were $5.9 \pm 1.0,26.4 \pm 0.2^{\circ} \mathrm{C}$ and 3.3 $\pm 1.3 \mathrm{mg} / \mathrm{L}$ over the bioassay period.

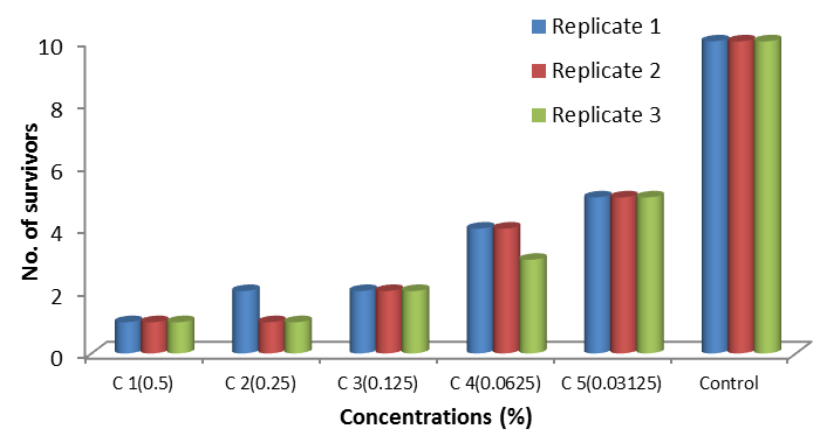

Figure 3. Survival of fingerlings of C. gariepinus (10 animals) exposed to Petals shampoo over 96 hours

\subsection{Comparison of Survivals in Treatment and Control Concentrations}

Results of the pair-wise comparison in the number of survivors of fingerlings of $C$. gariepinus exposed to the $0.125 \%$ and $0.03125 \%$ toxicant concentrations of Vinoz shampoo differed significantly with those of the control (sig.t $=0.001$ and 0.002 respectively) at $\mathrm{P}<0.05$. Similarly, with Gentelle shampoo toxicant solutions, the number of survivors in the $0.125 \%$ and $0.03125 \%$ concentrations differed significantly with those of their control solutions (sig. $\mathrm{t}=0.002$ and 0.003 respectively).

\subsection{Mean Lethal Concentrations $\left(\mathrm{LC}_{50}\right)$ of Toxicants}

Using the arithmetic graphical method (AGM), LC $\mathrm{C}_{50 \mathrm{~s}}$ for Vinoz shampoo were $0.0156 \%$ for replicate 1 , $0.0209 \%$ for replicate 2 and $0.0219 \%$ for replicate 3 . With the logarithmic graphical method (LGM), $\mathrm{LC}_{50 \text { s }}$ were $0.9141 \%$ for replicate $1,0.9016 \%$ for replicate 2 and $0.9016 \%$ for replicate 3 . However, with the probit graphical method (PGM), $\mathrm{LC}_{50 \text { s }}$ for replicates 1,2 , and 3 were $0.0141 \%, 0.0188 \%$ and $0.0188 \%$ respectively. Mean $\mathrm{LC}_{50 \mathrm{~s}}$ therefore were $0.0195 \%_{\mathrm{AGM}}, \quad 0.9058 \%_{\mathrm{LGM}}$, and $0.0172 \%$ PGM .

With the AGM, LC 50 s for Gentelle shampoo were $0.0313 \%$ for replicate $1,0.0266 \%$ for replicate 2 and $0.0266 \%$ for replicate 3 and with the LGM, LC $\mathrm{L}_{50 \text { s }}$ were $0.8710 \%$ for replicate $1,0.8954 \%$ for replicate 2 and $0.8954 \%$ for replicate 3 . With the PGM, LC $\mathrm{C}_{50 \mathrm{~s}}$ for replicates 1,2 , and 3 were $0.0313 \%, 0.0266 \%$ and $0.0266 \%$ respectively. Mean $\mathrm{LC}_{50 \mathrm{~s}}$ were $0.0281 \%{ }_{\mathrm{AGM}}$, $0.8873 \%_{\mathrm{LGM}}$, and $0.0281 \%_{\mathrm{PGM}}$.

With Petals shampoo, $\mathrm{LC}_{50 \text { s }}$ with the AGM was $0.0313 \%$ for each of replicates 1,2 and 3 and with the LGM, it was $0.8710 \%$ for each of replicates 1,2 and 3. However, with the PGM, $\mathrm{L}_{\mathrm{C} 50}$ values for replicates 1, 2, and 3 were $0.0156 \%, 0.0188 \%$ and $0.0188 \%$ respectively. Mean $\mathrm{LC}_{50 \mathrm{~s}}$ therefore were $0.0313 \%_{\mathrm{AGM}}, 0.8710 \%_{\mathrm{LGM}}$, and $0.0177 \%$ PGM. 


\section{Discussion}

Acute toxicity studies have been recognized as the first step in determining the water quality requirements of fish and so reveal toxicant concentrations that cause mortality even at short exposure. They have further been used to derive water quality guidelines for regulatory measures [14]. Biological monitoring using a series of assays having different endpoints could allow a sensitive approach to predict the potential risk of shampoos which is helpful in formulating the 'safe levels' of such bioaccumulative chemicals. The observed effects of the hair shampoo effluents on fish in the current research indicates that caution should be exercised in allowing these xenobiotics into the aquatic environment, especially in excessive amounts.

Though the fingerlings were not fed during definitive test periods, the diluents water quality underwent observable degradations, most probably due to the effects of the toxicants and their intermediate bi-products $[15,16]$ as well as physiological wastes from the animals. Effect on fingerlings included immediate hyperactivity of the fish body parts, similar to observations made by Ogundiran et al. [17] on the catfish.

Obviously, survival rates in this study increased with decrease in toxicant concentrations of the three brands of shampoos used, especially with Petals shampoo, in consonance with mortalities increasing with concentrations and varying with brand of shampoo; with the $0.5 \%$ toxicant concentration and Vinoz shampoo showing the highest toxicity. $\mathrm{LC}_{50 \text { s }}$ for Vinoz, Gentelle and Petals did not differ markedly and were in the order of magnitude Gentelle $=$ Petals $>$ Vinoz $_{\mathrm{AGM}}$, Vinoz $>$ Gentelle $>$ Petals $_{\text {LGM }}$ and Gentelle $>$ Petals $>$ Vinoz PGM $_{\text {. The observed }}$ homogeneity in survivorship of $C$. gariepinus in the different concentrations of Vinoz indicates that dilution did not exert marked effect on the toxicity of the xenobiotic. Conversely, the observed heterogeneity in survivorship of the fish at the different concentrations of Gentelle and Petals shampoos clearly indicate that dilution had effects on the toxicity of the xenobiotics. The contributions to mean variations by the $0.0313 \%$ and control concentrations clearly indicate the negligible toxicities exerted by very low or absence of toxicant in toxicity tests.

\section{Summary and Conclusion}

Very low concentrations of the hair care shampoos used as toxicants induced high lethal toxicities in the test organisms. Vinoz shampoo was more toxic to Clarias gariepinus fingerlings than Gentelle and Petal Shampoos. All the Shampoos induced toxic stress in form of behavioural changes in the fish. Mortalities increased with increasing concentrations of the toxicants.

The very low $\mathrm{LC}_{50 \text { s }}$ recorded in this study indicates that high toxicities were induced by very low concentrations of the xenobiotics. This thus classifies these toxicants as deleterious to aquatic biotopes.

\section{Recommendation}

Local regulatory agencies such as the National Environmental Standards and Regulations Enforcement
Agency (NESREA), Federal Ministry of Environment (FMEnv) and Federal Environmental Protection Agency (FEPA) should strictly monitor and enforce the relevant laws to protect aquatic lives, especially Clarias gariepinus.

\section{Acknowledgement}

We acknowledge the assistance of Transcontinental Petrotech (Nigeria) Limited for giving out their in-situ equipment for this research.

\section{References}

[1] Richtler, H.J. and Knaut, J. "World prospects for surfactants" in Proceedings of 2nd world surfactants congress organised by Syndicat National des fabricants d' Agents Surface et de produits Auxiliares industriels Paris, 1988, 3-58.

[2] Adewoye, S.O., Fawole, O.O., Owolabi, O.D. and Omotosho, J.S. "Toxicity of cassava waste water effluents to African Catfish: Clarias gariepinus”, Ethiop. J. Sci., 28 (7): 189-194, 2005.

[3] Awasthi, S.K., Khanna, R.K. and Trivedi, R.K. Surfactant industry Emerging Trends; Managing Environmental Risks: Challenges facing Detergents in the 21st century. R. Trivedi (Ed). Delhi: Tata McGraw Hill, 2000.

[4] Adham, K.G., Hamed, S.S., Ibrahim, H.M. and Saeh, R.A. "Impaired functions of Nile Tilapia, Oreochromis niloticus from polluted waters”, Acta Hydrochemical et Hydrobiological, 2002.

[5] Ndu, B.E. Impact of Karate (Lambda cyhalothrin) insecticide on the uptake of some major cations and anions in gills of freshwater catfish, Heteroclarias (Hybrid) fingerlings. B.Sc. Thesis. Micheal Okpara University of Agriculture, Umudike, Nigeria.2004; 70pp.

[6] Abbas, H.H.H.and Mahmood, H.M. "The toxicological effect of water pollution on the Nile Tilapia fish (Oreochromis niloticus) collected from four sites along the River Nile”, J. Egypt Vet. Med. Assoc., 63: 307-323, 2003.

[7] Abbas, H.H.H. and Mahmood, H.M. "Haematological and biochemical changes in Oreochromis aureus and Clarias gariepinus exposed to mixtures of Copper and Lead salts”, Egypt J. Basic. Appl. Physiol., 3: 89-106, 2004.

[8] Buikema, A.L. Jr. and Cairns, J. Jr. (Eds). Aquatic Invertebrate Bioassays. ASTM Spec. Tech. Publ., 1980, 715: 209.

[9] Bellan, G. Manual of Methods in Aquatic Environment Research. Part 7. Selected Bioassays for the Mediteranean. (Tests used by the FAO (GFCM)/ UNEP Joint coordinate 1 project on Pollution in the Mediterranean, FAO Fish. 1981; Tech. Paper 208: 37.

[10] Ward, C.S. and Parrish, P.R. Manual of Methods in Aquatic Environment Research. Part 6 Toxicity Tests. 1981; FAO Fish. Tech. Paper, 185: 23.

[11] Ward, G.S. and Parrish, P.R. Manual of Methods in aquatic environmental research. Part 6. Toxicity Tests. 1982; FAO Fisheries Technical Paper, No. 185 FIRI/T185.

[12] Reish, D.J. and Oshida, P.S. Manual of Methods in Aquatic Environment Research, Part 10. Short-Term Static Bioassays. 1986; F.A.O. Fish Tech. Paper 24, 62 pp.

[13] Reish, D.L. and Oshida, O.S. Manual of Methods in aquatic environment research. Part 10. Short-term bioassays. 1987; FAO Fisheries Technical Paper No. 247. Rome, 62 pp.

[14] World Health Organisation (WHO). International program on chemical safety environment health criteria 169 Linear Alkylbenzene Sulphonates and related compounds. World Health Organisation, Geneva, 1996.

[15] Okpokwasili, G.O. and Nwabuzo, C.N. "Primary biodegradation of anionic surfactants in laundary detergents", Chemosphere, 17: 2175-2182, 1988.

[16] Okpokwasili, G.C. and Olisa, A.O. "Biodegradations of surfactants. I. Liquid detergents and shampoos”, Water Research, 27: 1425-1429, 1991.

[17] Ogundiran, M.A., Fawole, O.O. and Adewoye, S.O. "Effects of soap and Detergent Effluents on the Haematological profiles of Clarias gariepinus”, Science Focus, 12 (1): 84-88, 2007. 